\title{
Evaluating the profitability of flexibility
}

DOI:

10.1109/PESGM.2012.6344848

Link to publication record in Manchester Research Explorer

\section{Citation for published version (APA):}

Ma, J., Silva, V., Ochoa, L. F., Kirschen, D. S., \& Belhomme, R. (2012). Evaluating the profitability of flexibility. In IEEE Power and Energy Society General Meeting/IEEE Power Energy Soc. Gen. Meet. https://doi.org/10.1109/PESGM.2012.6344848

\section{Published in:}

IEEE Power and Energy Society General Meeting|IEEE Power Energy Soc. Gen. Meet.

\section{Citing this paper}

Please note that where the full-text provided on Manchester Research Explorer is the Author Accepted Manuscript or Proof version this may differ from the final Published version. If citing, it is advised that you check and use the publisher's definitive version.

\section{General rights}

Copyright and moral rights for the publications made accessible in the Research Explorer are retained by the authors and/or other copyright owners and it is a condition of accessing publications that users recognise and abide by the legal requirements associated with these rights.

\section{Takedown policy}

If you believe that this document breaches copyright please refer to the University of Manchester's Takedown Procedures [http://man.ac.uk/04Y6Bo] or contact uml.scholarlycommunications@manchester.ac.uk providing relevant details, so we can investigate your claim.

\section{OPEN ACCESS}




\title{
Evaluating the Profitability of Flexibility
}

\author{
Juan Ma, Graduate Student Member, IEEE, Vera Silva, Luis F. Ochoa, Member, IEEE, \\ Daniel S. Kirschen, Fellow, IEEE, and Régine Belhomme, Member, IEEE
}

\begin{abstract}
As wind capacity becomes a larger component of the generation portfolio, more flexibility is required to cope with its uncertain and variable nature. In a competitive market environment, the provision and development of this flexibility is driven by the remuneration of flexibility providers. This paper proposes an approach to quantify the profit that market participants derive from providing flexibility services. This is based on the simulation of forward (day-ahead) and real-time balancing markets. In addition, a more flexible market design (rolling commitment) in which a periodic re-optimization is performed to take advantage of updated wind. Test results based on the IEEE RTS-96 are used to compare the profitability of flexibility for different market designs and to assess the effect of the wind forecast error and other parameters on this profitability. The results have shown that with the proposed market design and the associated payment scheme, generators can obtain profit for providing flexibility services as wind penetration increases and the error of the wind forecast and the flexible market design has a significant influence on this profitability.
\end{abstract}

Index Terms - day-ahead market, real-time balancing market, rolling-commitment, flexibility, integration of wind generation, generation profits

\section{INTRODUCTION}

$\mathrm{T}_{\mathrm{t} \text { tis }}$ HE rapid development of wind generation is increasing the uncertainty that the power system operators have to face and the variability in the net load that they have to handle. In order to cope with this increase in uncertainty and variability the system operator needs to have access to sufficient flexibility to maintain the demand-generation balance for all time-scales. A review of the recent literature shows that the concept of "flexibility" has been increasingly used in the context of the integration of intermittent renewable energy sources. This flexibility can be provided by generating [1-5], demand side management [6-8], energy storage [9-12] or interconnections with neighboring systems [13]. Even though the concept of flexibility is not new and it has long been used to follow demand variability and cope with the uncertainty due to generation outages and demand forecast the study of the relationship between flexibility and wind generation is still relatively new. Specific research studies in recent years [14-16] focus on the quantification of the need for

The work described in this paper was supported by EDF.

J. Ma and L. F. Ochoa are with the School of Electrical and Electronic Engineering, The University of Manchester, Manchester M13 9PL, U.K. (email: juan.ma@postgrad.manchester.ac.uk, luis_ochoa@ieee.org).

D. S. Kirschen is with the Department of Electrical Engineering at the University of Washington, Seattle, U.S.A. (e-mail: Kirschen@uw.edu).

V. Silva and R. Belhomme are with EDF R\&D (email: vera.silva@edf.fr, regine.belhomme@edf.fr) flexibility and its economic and environmental value in systems with wind generation. The remuneration of flexibility in a market environment has not yet been explored. In order to ensure that adequate economic signals are sent to flexibility providers this remuneration needs to include both the actual and opportunity costs of providing the service and incentives to encourage further investments in flexibility whenever this is required.

This paper presents an approach to calculate the overall profit that a provider of flexibility can obtain in both forward and the real-time (balancing) regulation markets. Two alternative market designs are compared: 1) traditional dayahead and real-time balancing and 2) "rolling clearing" that takes advantage of the periodically updated wind forecasts [17].

The rest of the paper is organized as follows: The definitions of "flexibility" and "profit from flexibility" are clarified in section 2. Section 3 describes the market model and the method used to calculate the profit. Test results to validate the model and assess the effects of various parameters on this profitability are presented in section 4. Finally, section 5 summarizes and concludes this work.

\section{FleXibility and Profit of Flexibility}

\section{A. Sources of Flexibility}

An actor in a power system (such as the system operator, a generation company, or a retailer) is deemed flexible if it has the ability to meet its obligations or achieve its objectives at a reasonable cost when faced with unforeseen events or actions. Similarly, a power system has enough flexibility if it has in place the procedures and resources needed to counteract the effects of uncertainties without resorting to undesirable measures such as involuntary load shedding. Flexibility thus involves a combination of resources (such as agile generating units, demand response, energy storage and interconnections with neighboring systems) and the contractual agreements and procedures needed to muster these resources in a timely fashion.

For the sake of clarity this paper focus on the flexibility that conventional generating units can provide in response to variations in the net demand (gross demand minus wind generation) and deviations between the forecasted and actual wind. This approach can, however, be applied to alternative sources of flexibility.

A conventional generating unit can contribute to flexibility if it has some (or all) of the following capabilities:

- ability to synchronize or disconnect in short time

- dispatched generation output is below its maximum 
output and /or dispatched generation above its minimum stable generation

- ability to increase or decrease its power output rapidly (ramping capability)

In addition, the need for flexibility is influenced by the market design. The aspects that impact this are:

- gate closure time of the forward market (e.g., day-ahead)

- gate closure time of the real-time balancing market

- periodicity and accuracy of the wind generation forecasts

- reserve requirements and other security margins

- ability of some participants to bid strategically in the forward and/or real-time balancing markets

By influencing the need for flexibility the market design also affects its profitability. The analysis of the relation between the market design and the profit of flexibility is one of the objectives of this paper.

\section{B. Sources of flexibility profit}

The integration of large amounts of wind generation increases the flexibility that needs to be provided by conventional generation. This increase is mainly driven by the need for compensating the natural and relatively slow fluctuations of wind power and the additional deployable reserve capacity required to cater for wind uncertainty.

The flexibility required to meet the above mentioned requirements can be provided by conventional generation in the form of flexibility services, described as follows:

- modulation of generation output over time, to follow variable net demand. This service is traded in the forward energy market;

- available spare capacity for reserve (in this work we consider reserve services in the tertiary regulation interval). This service is traded in the forward reserve market

- real time adjustments of the generation output, at the request of the system operator, to compensate the differences between forecasted and realized wind generation. This service is traded in the real-time balancing market.

The profit obtained from the provision of the above mentioned services is defined here as flexibility profit. In this work, to avoid distortions resulting from strategic bidding or market power, this is assumed to be obtained from trading these services in centrally operated markets with perfect competition.

\section{FleXiBiLity MARKet MODEL}

\section{A. Market Model with Periodic Re-optimization}

Centrally operated energy and reserve markets are typically cleared 24 hours ahead of electricity delivery time and are designated here as forward markets. As the proportion of wind generation increases this day-ahead market clearing procedure might not be the best option. The accuracy of a wind generation forecast for a 3 to 6 hour horizon [18] is significantly higher than for a 24-hour forecast horizon. It is envisaged that if generation scheduling is periodically reoptimized, using updated wind generation forecasts, as implemented in the WILMAR model [17], the impact of wind generation on the need for flexibility can be reduced. A better knowledge of the wind generation at the moment of the clearing of the forward market improves the use of generation.

This forward market needs to be complemented by a realtime balancing market, where the system operator obtains the short-term flexibility required to compensate for the load/generation imbalances.

Fig.1 illustrates the structure of this market design for the example of having wind generation forecast is updates every 6 hours, and the forward market is cleared 4 times a day. Between these periodic re-optimizations, the real time market operates with shorter gate closure times.

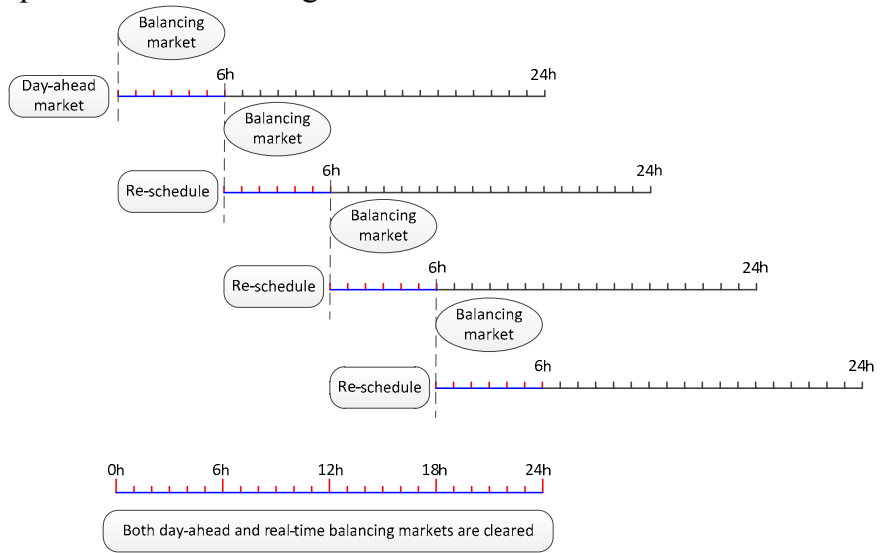

Fig. 1. Structure of the forward and real-time balancing markets assuming that the wind generation forecast is updated every 6 hours

\section{B. Forward Market Model}

In a perfectly competitive market, the clearing price is equal to the marginal cost of the marginal unit. However, if this cost is used as the market-clearing price, some generating units will never be able to recover their start-up and no-load costs, commonly included in the generation bids. In order to assume that units bid their marginal cost, in our model, the market-clearing price is modified to represent an "adjusted marginal cost" of the marginal unit [19].

This adjusted marginal cost of each generator is the sum of the following quantities:

- marginal cost

- start-up cost amortized over the energy produced by the unit over all the hours it is running

- no-load cost amortized over the energy produced during the hour considered

The market clearing is based on an unit commitment calculation, with the objective of cost minimization, is performed using the latest wind generation and demand forecasts:

\section{Objective function}

$$
\operatorname{Min}\left[\begin{array}{l}
\sum_{i=1}^{N} \sum_{t=1}^{T} u(i, t) \mathrm{C}_{N L}(i)+\sum_{i=1}^{N} \sum_{t=1}^{T} u(i, t) \mathrm{C}_{I N C}(i, t) p(i, t) \\
+\sum_{i=1}^{N} \sum_{t=1}^{T} \mathrm{C}_{S T}(i, t)
\end{array}\right]
$$

where $u(i, t)$ is the decision variable representing the on/off 
status of unit $i$ during period $t, \mathrm{C}_{N L}(i)$ is the no-load cost of generator $i, p(i, t)$ is the decision variable indicating the power produced by generator $i$ during period $t$, and $\mathrm{C}_{S T}(i, t)$ is the start-up cost of generator $i$ during period $t$.

This is subjected to the following set of constraints.

\section{System hourly power balance}

$$
\sum_{i=1}^{N} p(i, t) u(i, t)=D_{f}(t)-W_{f}(t) \quad \forall t=1, \ldots, T
$$

where $D_{f}(t)$ and $W_{f}(t)$ represents the forecasted load and wind generation during period $t$ in the forward market, respectively.

\section{Reserve requirements}

$$
\begin{array}{r}
\sum_{i=1}^{N} u(i, t)\left[P_{M A X}(i)-p(i, t)\right] \geq R_{s}(t)+\min \left\{3.5 \sigma(t) W C, W_{f}(t)\right\} \\
\sum_{i=1}^{N} u(i, t)\left[p(i, t)-P_{M I N}(i)\right] \geq \min \left\{3.5 \sigma(t) W C, W C-W_{f}(t)\right\} \\
\forall t=1, \ldots, T
\end{array}
$$

where $P_{M A X}(i)$ and $P_{\text {MIN }}(i)$ are the maximum capacity and the minimum stable generation of generator $i, R_{S}(t)$ is the basic upward reserve requirement for generation outage during period $t, \sigma(t)$ indicates the normalized standard deviation of the wind forecast error during period $t . W C$ is the total wind capacity. Here we assume that the demand can be perfectly predicted and we only focus on the additional reserve that is required by the inaccurate wind forecast.

The traditional system upward reserve requirement is equal to the capacity of the largest committed generating unit. To reduce the risk associated with the wind forecast error, an additional reserve requirement equal to $\min \left\{3.5 \sigma(t) \times W C, W_{f}(t)\right\}$ is added to the basic upward reserve requirement. When $W_{f}(t)$ is found to be smaller than $3.5 \sigma(t) \times W C$, the additional reserve requirement is equal to the forecasted wind generation since the worst case scenario is that none of the forecasted wind is realized at delivery time. This method is based on [20] and 3.5 corresponds the number of standard deviations required to capture most of wind forecast imbalances without changing the risk level accepted in a system without wind. Downward reserve constraint is be set a $\min \left\{3.5 \sigma(t) \times W C, W C-W_{f}(t)\right\} \quad$ to cover an underestimation in wind generation.

In addition all the generation dynamic constraints that affect the deployment o flexibility are considered.

\section{Generation limits}

$$
P_{M I N}(i) \leq p(i, t) \leq P_{M A X}(i) \quad \forall t=1, \ldots, T
$$

\section{Minimum up time and minimum down time}

$$
\begin{aligned}
& {\left[T_{\text {up }}(i)-t_{\text {on }}(i, t-1)\right][u(i, t)-u(i, t-1)] \geq 0} \\
& {\left[T_{\text {down }}(i)-t_{\text {off }}(i, t-1)\right][u(i, t-1)-u(i, t)] \geq 0}
\end{aligned}
$$

where $T_{u p}(i)$ and $T_{\text {down }}(i)$ are the minimum up and down time of generator $i$. $t_{\text {on }}(i, t-1)$ and $t_{\text {off }}(i, t-1)$ indicates the number of periods that generator $i$ has been on or off, respectively.

\section{Maximum ramp-up and ramp-down}

$$
\begin{aligned}
& p(i, t-1)-p(i, t) \leq \Delta P_{u p}^{M A X}(i) \\
& p(i, t)-p(i, t+1) \leq \Delta P_{\text {down }}^{\text {MAX }}(i)
\end{aligned}
$$

$\Delta P_{u p}^{M A X}(i)$ and $\Delta P_{d o w n}^{M A X}(i)$ are the ramp-up and ramp-down limit of generator $i$.

Once the market clearing is performed and the scheduling of each generator $P(i, t)$ is known, the adjusted marginal cost of generator $i$ during period $t$ is calculated as follows:

$$
C_{A D J}(i, t)=C_{I N C}(i, t)+\frac{C_{S T}(i)}{\sum_{t_{o n}}^{t_{o f f}} P(i, t)}+\frac{C_{N L}(i)}{P(i, t)}
$$

The market-clearing price is then given by:

$$
\pi_{E}(t)=\max _{i}\left[\mathrm{C}_{A D J}(i, t)\right]
$$

All generating units scheduled to provide energy in the forward market are paid the adjusted market-clearing price, for every MWh produced at each hour. Generators that are providing reserve are remunerated on the basis of their lost opportunity cost (LOC). This LOC is the difference between the market-clearing price for energy and their marginal cost of production, times the amount of reserve that they are providing.

\section{Real-time Balancing Market Model}

Deviations resulting from wind forecast errors are cleared in the real-time balancing market. We assume that this market is perfectly competitive, so the bids for up/down regulation are based on actual production costs. Conventional generating units thus offer up regulation at their marginal cost of producing energy and bid down regulation at minus this marginal cost which means that the generator is willing to reduce their generation output by paying back to the market for the equivalent amount of power at this price. The real-time balancing market is cleared every hour and is also modeled as a cost minimization problem.

\section{Objective function}

If the wind power forecast was higher than the delivered wind generation, then up-regulation from conventional generating units is needed:

$$
\operatorname{Min}\left[\sum_{i=1}^{N} r_{u p}(i, t) * \operatorname{Bid}_{u p}(i)\right]
$$

where $\operatorname{Bid}_{u p}(i)$ is the up-regulation bid of generator $i$ for period t. $r_{u p}(i, t)$ is the decision variable indicating the upregulation provided by generator $i$ for period $t$.

On the other hand, if the wind forecast is found lower than the actual wind, conventional generating units must provide down-regulation: 


$$
\operatorname{Min}\left[\sum_{i=1}^{N} r_{\text {down }}(i, t) * \operatorname{Bid}_{\text {down }}(i)\right]
$$

where $\operatorname{Bid}_{\text {down }}(i)$ is the down-regulation bid of generator $i$ in period $t . r_{\text {down }}(i, t)$ is the decision variable indicating the down-regulation provided by generator $i$ in period $t$.

Since network constraints are outside the scope of this paper, at each hour, all the units provide regulation in the same direction.

\section{Regulation power constraints}

If up regulation is needed:

$$
\begin{gathered}
\sum_{i \in A} r_{u p}(i, t)=\Delta R_{u p}(t) \\
r_{u p}(i, t) \leq \min \left[\Delta P_{u p, M A X}(i), P_{M A X}(i)-P(i, t)\right]
\end{gathered}
$$

where $\Delta R_{u p}(t)$ is the total up regulation requirement in period t. $P(i, t)$ is the scheduled generation output of generator $i$ in period $t$ known from the clearing of the forward market.

If down regulation is needed:

$$
\begin{gathered}
\sum_{i \in A} r_{\text {down }}(i, t)=\Delta R_{\text {down }}(t) \\
r_{\text {down }}(i, t) \leq \min \left[\Delta P_{\text {down,MAX }}(i), P(i, t)-P_{\text {MIN }}(i)\right]
\end{gathered}
$$

where $\Delta R_{\text {down }}(t)$ is the total down regulation requirement in period $t$.

\section{Calculation of the Flexibility Profit}

The total profit obtained by a company corresponds to the sum of the profits collected in the forward and real-time balancing markets and are calculated as follows.

First, the total profit derived from the sale of energy and reserve on the forward markets corresponds to the revenues collected minus the costs involved in generating energy and providing flexibility.

\section{Revenue from energy for generator $A$}

$$
S_{E}(A)=\sum_{\mathrm{i} \in \mathrm{A}} \sum_{\mathrm{t}=1}^{\mathrm{t}=\mathrm{T}} \pi_{\mathrm{E}}(t) P(i, t)
$$

\section{Revenue from reserve for generator $A$}

$$
\begin{aligned}
& S_{R}(A)=\sum_{i \in A} \sum_{t=1}^{t=T} u(i, t) C_{O P P}(i, t)\left[P_{M A X}(i)-P(i, t)\right] \\
& =\sum_{i \in A} \sum_{t=1}^{t=T} u(i, t) \times\left[\pi_{E}(t)-C_{A D J}(i, t)\right] \times\left[P_{M A X}(i)-P(i, t)\right]
\end{aligned}
$$

where $C_{O P P}(i, t)$ represents the LOC of generator $i$ during period $t$.

\section{Total cost of generator $A$}

$$
\begin{aligned}
C(A)= & \sum_{i \in A} \sum_{t=1}^{T} u(i, t) C_{N L}(i)+\sum_{i \in A} \sum_{t=1}^{T} u(i, t) C_{I N C}(i, t) P(i, t) \\
& +\sum_{i \in A} \sum_{t=1}^{T} C_{S T}(i, t)
\end{aligned}
$$

\section{Total profit of generator $A$}

$$
\Omega(A)=S_{E}(A)+S_{R}(A)-C(A)
$$

In this work our focus is the profit obtained from providing the additional flexibility required to integrate wind generation. In order to isolate this profit we need to calculate the total profits obtained with and without wind, and take the difference between the two. This profit is then normalizes to obtain the profit from flexibility, per $\mathrm{MWh}$ of energy provided. For a given company, this is given by the following equation:

$$
\overline{\Omega_{F W}^{F l e x}}(A)=\frac{\Omega_{F W}^{W W}(A)}{\sum_{i \in A} \sum_{t=1}^{T} P_{F W}^{W W}(i, t)}-\frac{\Omega_{F W}^{N W}(A)}{\sum_{i \in A} \sum_{t=1}^{T} P_{F W}^{N W}(i, t)}
$$

where $\overline{\Omega_{F W}^{F l e x}}(A)$ is the average flexibility profit of company $\mathrm{A}$ obtained in the forward market, $\Omega_{F W}^{W W}(A)$ is the total profit for generator $\mathrm{A}$ in the forward market and $\sum_{i \in A} \sum_{t=1}^{T} P_{F W}^{W W}(i, t)$ is the total production of generator A traded in the forward market, both with wind (WW) penetration. $\Omega_{F W}^{N W}(A)$ is the total profit for generator $\mathrm{A}$ in the forward market and $\sum_{i \in A} \sum_{t=1}^{T} P_{F W}^{N W}(i, t)$ is its total generation traded in the forward market, both without wind $(\mathrm{NW})$ penetration.

The profit of company A obtained from flexibility services in the forward market $\Omega_{F W}^{F l e x}(A)$ is calculated as:

$$
\Omega_{F W}^{F l e x}(A)=\overline{\Omega_{F W}^{F l e x}}(A) \times \sum_{i \in A} \sum_{t=1}^{T} P_{F W}^{W W}(i, t)
$$

To this profit we add the profit obtained in the real-time balancing market, where all units providing up/down regulation are paid the clearing price $\pi_{R E}^{u p}(t)$ or $\pi_{R E}^{\text {down }}(t)$ (equal to the bid price of the last accepted MWh of up/down regulation).

The profit that generator A collects from providing up regulation can be calculated as follows:

\section{Revenue of generator A from up regulation}

$$
I_{R T}^{u p}(A)=\sum_{i \in A} \sum_{t=1}^{t=T} \pi_{R T}^{u p}(t) R_{u p}(i, t)
$$

Cost of generator $A$ for providing up regulation

$$
C_{R T}^{u p}(A)=\sum_{i \in A} \sum_{t=1}^{T} \operatorname{Bid}_{u p}(i, t) R_{u p}(i, t)
$$

\section{Profit from up regulation for generator $A$}

$$
\Omega_{R T}^{u p}(A)=I_{R T}^{u p}(A)-C_{R T}^{u p}(A)
$$

The profit that generator A collects from providing down regulation can be calculated as follows:

Revenue of generator A from down regulation

$$
I_{R T}^{\text {down }}(A)=\sum_{i \in A} \sum_{t=1}^{T}\left|B_{i d}(i, t) R_{\text {down }}(i, t)\right|
$$

Cost of generator A for providing down regulation

$$
C_{R T}^{\text {down }}(A)=\sum_{i \in A} \sum_{t=1}^{t=T}\left|\pi_{R T}^{\text {down }}(t) R_{\text {down }}(i, t)\right|
$$

\section{Profit from down regulation for generator $A$}




\section{Accepted Paper}

$$
\Omega_{R T}^{\text {down }}(A)=I_{R T}^{\text {down }}(A)-C_{R T}^{\text {down }}(A)
$$

Notice here that the revenue of generators from down regulation is actually the savings of their production cost by reducing the generation output, and their cost is the money that they pay back to the market for the equivalent amount of power.

The total flexibility profit obtained by a company is the sum of the profits it obtains from providing flexibility services in the forward and real-time balancing market:

$$
\Omega_{\text {Flex }}(A)=\Omega_{F W}^{F l e x}(A)+\Omega_{R T}^{u p}(A)+\Omega_{R T}^{\text {down }}(A)
$$

\section{E. Wind Modeling}

The wind power generation pattern of a wind farm is based on historical hourly wind data for one year obtained from [21]. Multiplying these values by the nominal capacity of the wind farm gives the aggregated wind power curve. The wind forecast error is assumed to depend on the forecast horizon, as illustrated in Fig. 2.

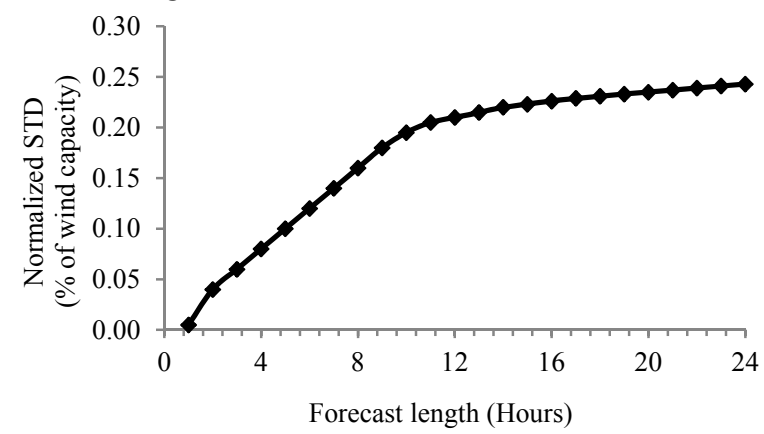

Fig. 2. Normalized standard deviation of the wind generation forecasting error as a function of the forecasting horizon

The forecast errors are modeled using a zero-mean normallydistributed random variables $\theta_{w t}$ with standard deviation (STD) $\sigma_{w t}$ for $\mathrm{t}=1, \ldots, \mathrm{T}$. The wind forecast is calculated by adding a forecast error to the actual wind data for each specific hour. This wind forecast error is assumed to be compensated by the balancing power traded in the real-time balancing market.

\section{CASe Study}

\section{A. Test System}

The proposed approach has been tested with a system where three generating companies share the market. Each of these companies owns 10 identical generating units with an individual maximum capacity of 100MW. The cost curve of the generating units is represented using a three-segment piecewise linear approximation.

The difference between the units is their level of flexibility, as shown in Table 1. Generating units of company A are flexible, those of company $\mathrm{B}$ have a medium flexibility, and those of company $\mathrm{C}$ are low flexible. and are the abscissa of the elbow points of this curve, while and are the slope of Differences in flexibility between these units have been introduced in the minimum up- and down-times, in the rampup and ramp-down rates as well as in the shape of the cost curves and the start-up costs. Since each company has an equal share of the total $3000 \mathrm{MW}$ installed capacity, biases in the comparison of profits from flexibility of each company are avoided.

TABLE I

PARAMETERS OF THE GENERATING UNITS OF THE 3 COMPANIES

\begin{tabular}{|l||c|c|c|}
\hline \hline Company & A & B & C \\
\hline Portfolio flexibility & High & Medium & Low \\
\hline \hline $\mathrm{P}_{\mathrm{MIN}}[\mathrm{MW}]$ & 25 & 25 & 25 \\
\hline $\mathrm{P}_{\mathrm{MAX}}[\mathrm{MW}]$ & 100 & 100 & 100 \\
\hline $\mathrm{C}_{\mathrm{NL}}[\$ / \mathrm{h}]$ & 117.6 & 210.1 & 132.0 \\
\hline $\mathrm{C}_{\mathrm{INC}}[\$ / \mathrm{MWh}]$ & 38.1 & 19.1 & 11.8 \\
\hline $\mathrm{C}_{\mathrm{ST}}[\$]$ & 10 & 566 & 4468 \\
\hline $\mathrm{T}_{\mathrm{up}}[\mathrm{h}]$ & 1 & 4 & 8 \\
\hline $\mathrm{T}_{\mathrm{down}}[\mathrm{h}]$ & 1 & 2 & 5 \\
\hline$\Delta \mathrm{P}_{\text {up }}^{\mathrm{MAX}}[\mathrm{MW} / \mathrm{h}]$ & 100 & 50 & 25 \\
\hline$\Delta \mathrm{P}_{\mathrm{down}}^{\mathrm{MAX}}[\mathrm{MW} / \mathrm{h}]$ & 25 & 50 & 100 \\
\hline $\operatorname{Bid}_{\text {up }}[\$ / \mathrm{MWh}]$ & 38.1 & 19.1 & 11.8 \\
\hline $\operatorname{Bid}_{\mathrm{down}}[\$ / \mathrm{MWh}]$ & -38.1 & -19.1 & -11.8 \\
\hline \hline
\end{tabular}

\section{B. Effect of the Wind Penetration}

In order to show how wind generation affects the profitability of providing flexibility, four different levels of wind energy penetration were considered $(0 \%, 10 \%, 20 \%$, and $30 \%$ of annual gross demand). Demand data is based on historical hourly demand data for one year obtained from [21].

It is assumed here that the production cost of wind generation is zero. Fig. 3 shows how the markets share of the three companies, calculated by dividing the annual energy production of each portfolio by the total annual demand, changes with the wind penetration. It is shown that the wind penetration eats up part of the market shares of all the conventional generating units due to its advantage in terms of cost. However, the reduction rates of the market shares for different technologies are different. The reduction rate of the market share for the high-flexible portfolio slows down with higher penetrations of wind power because more flexibility is required from them to accommodate the wind. On the contrary, the reduction rate of the market share for the lowflexible portfolio increases because they have little contribution in providing flexibility services.

Fig. 4 shows that the average profit from flexibility services in the forward market (in $\$ / M W h$ ) increases with the wind penetration for all the types of units. As flexibility requirement increases with penetrations, the high-flexible units are more likely to become marginal units, so the average uniform market clearing price is getting higher. To some extent, this is helpful to compensate their losses due to the reduction of their market shares.

Fig. 5 shows the overall profit (in Million\$/year) from flexibility services in the forward market for the different types of units.

Fig. 6 shows how the overall profit (in $\mathrm{k} \$ / \mathrm{h}$ ) from flexibility services in the real-time balancing market. It is seen that all the technologies obtain more profit from flexibility services as wind penetration increases. Comparing with the high and medium flexible units, the flexibility profit for low flexible units is relatively small because they are difficult to provide regulation services.

Fig. 7 shows that, if both markets are considered together, 


\section{Accepted Paper}

the total profitability of flexibility services (in Million \$) increases with the wind penetration. It is also seen that most of the flexibility profit comes from the forward market.

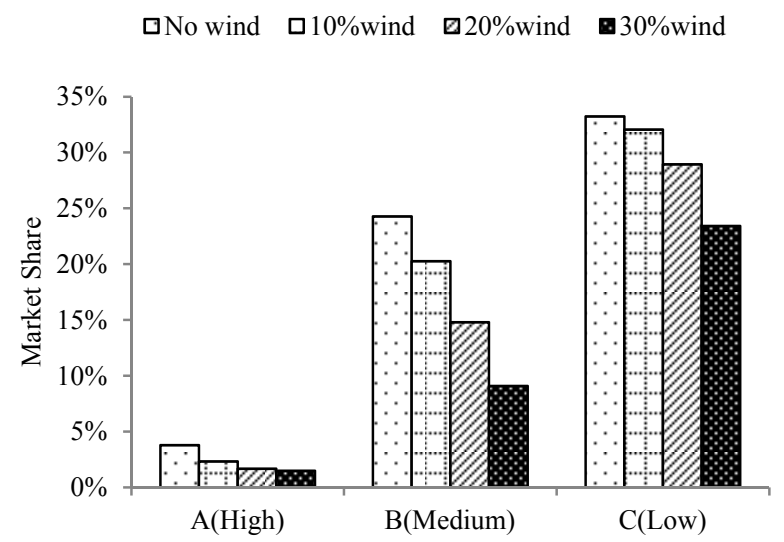

Fig. 3. Market share of conventional technologies for different penetrations of wind generation

口10\%wind $\square 20 \%$ wind $30 \%$ wind

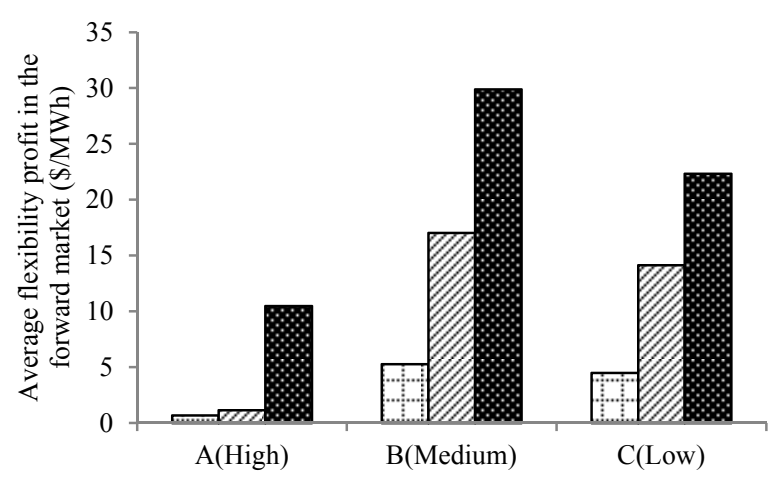

Fig. 4. Average profit from flexibility services in the forward market for the different types of units (in $\$ / M W h$ )

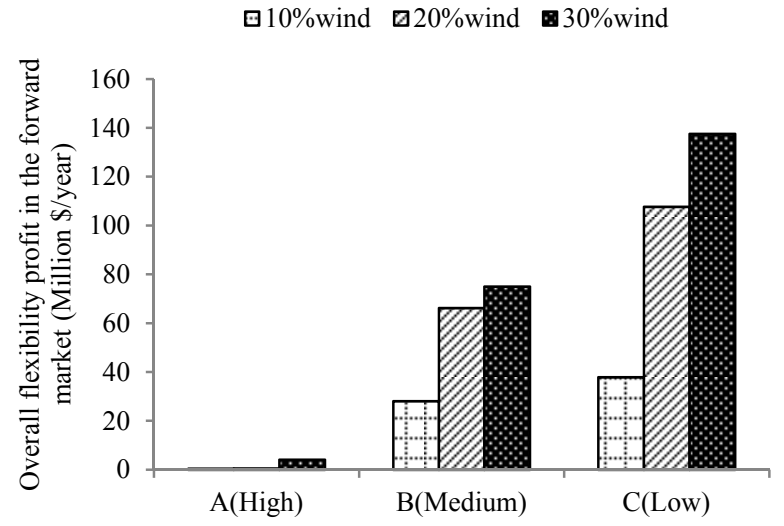

Fig. 5. Overall profit from flexibility services in the forward market for the different types of units (in Million\$/year)

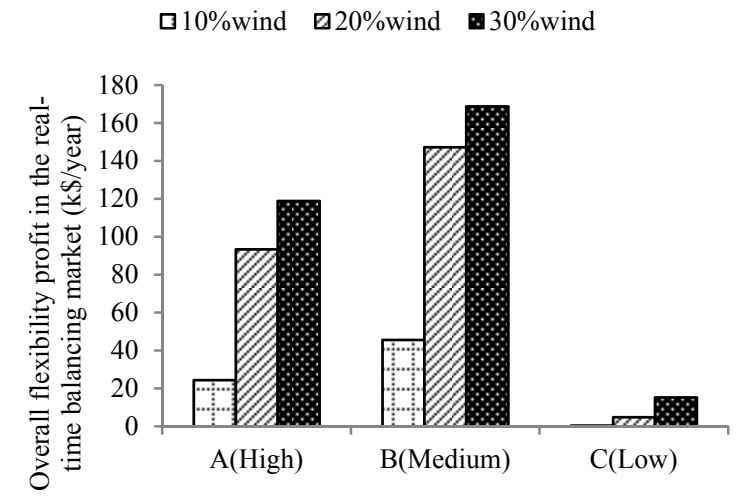

Fig. 6. Overall profit from flexibility services in the real-time balancing market for the different types of units (in $\mathrm{k} \$ /$ year)

口 $10 \%$ wind $\square 20 \%$ wind $\mathbf{0} 30 \%$ wind

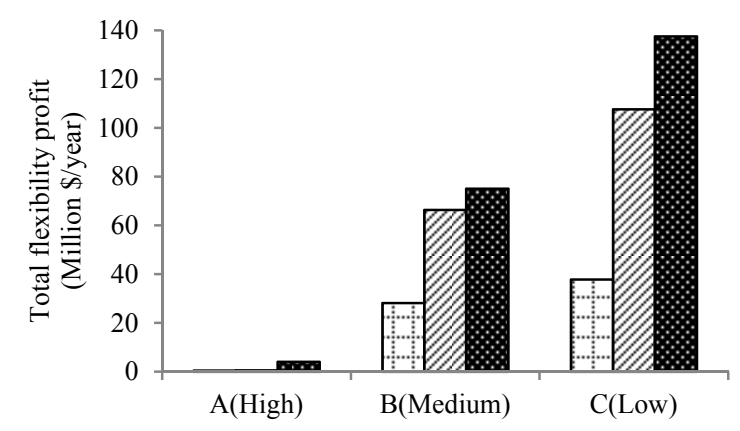

Fig. 7. Total flexibility profit from both forward and real-time balancing markets (\$/year)

\section{Effect of the Accuracy of the Wind Forecast}

Fig. 8 shows two different patterns of standard deviation of the wind forecast error over the wind forecast horizon. Fig. 9 and Fig. 10 compare the corresponding overall profits in the forward and regulation markets, respectively. As one would expect, more accurate wind forecasts reduces the need for flexibility services and hence its profitability. For both low and high accuracy forecasts, the profitability increases with the wind penetration.

As Fig. 11 shows, the total flexibility profit follows the same pattern as the profitability in the forward market because the amount of flexibility services in this market is larger than in the real-time market.

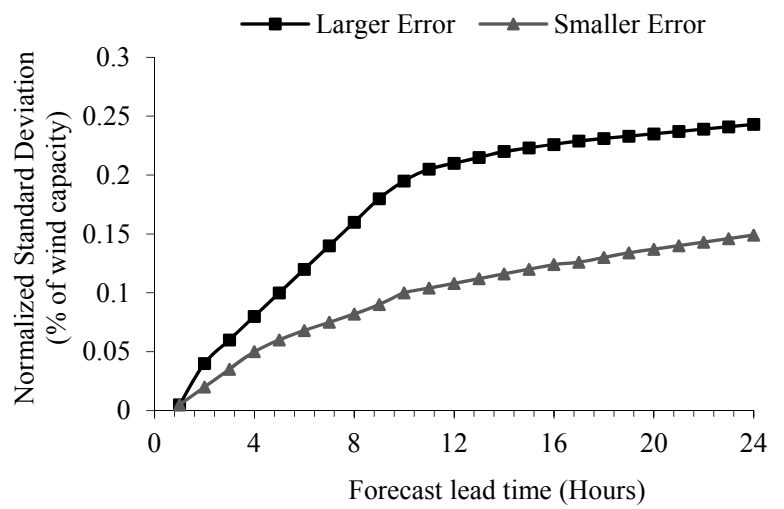

Fig. 8. Patterns of normalized standard deviation of wind forecast error (expressed as a fraction of the wind generation capacity) 


\section{Accepted Paper}

- Small Error Large Error

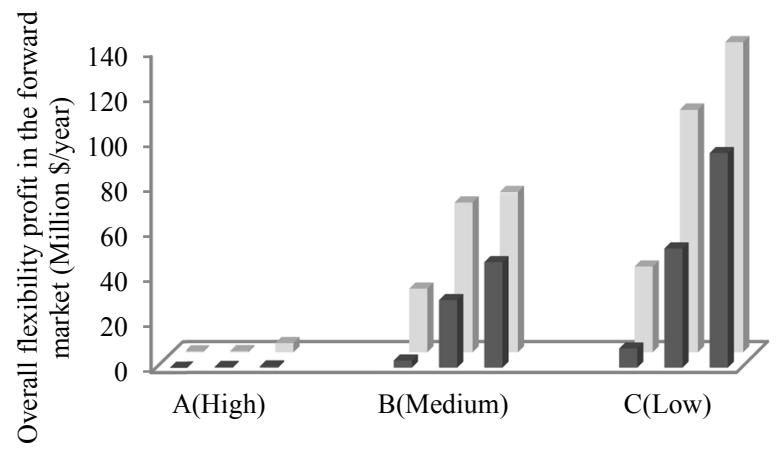

Fig. 9. Overall profit (Million \$/year) from flexibility services in the forward market for two patterns of wind forecast error as a function of the penetration of wind generation

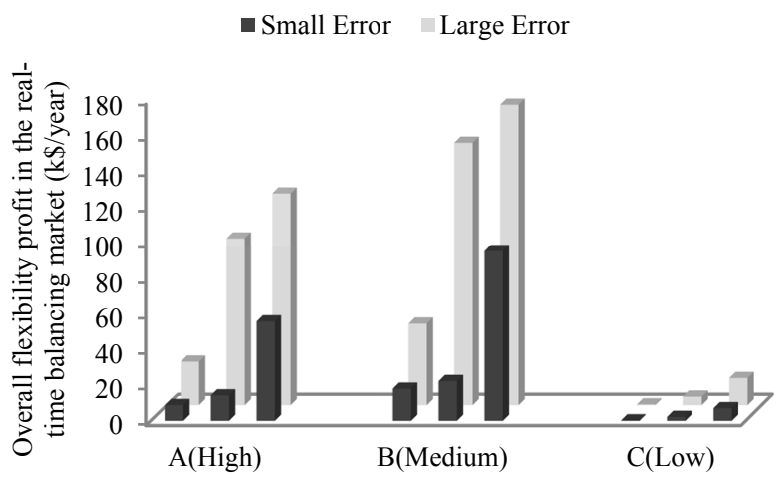

Fig. 10. Overall profit ( $\mathrm{k} \$$ year) from flexibility services in the real-time market for two patterns of wind forecast error as a function of the penetration of wind generation.

- Small Error $\square$ Large Error

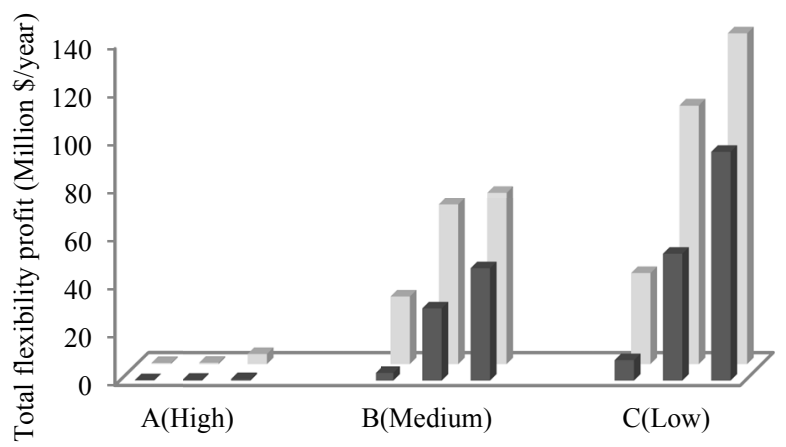

Fig. 11. Total flexibility profit (Million \$/year) obtained from both the forward and the real-time markets for two patterns of wind forecast error as a function of the wind penetration

\section{Effect of Rolling Market Clearing}

Fig. 12, Fig. 13 and Fig. 14 show that periodically reclearing the market with updated wind forecasts reduces the profitability of flexibility services in both the forward and real-time markets as well as the total annual profit. These results are based on the low accuracy forecasts (large error) of Fig. 8. 6h Rolling Clearing No Rolling Clearing

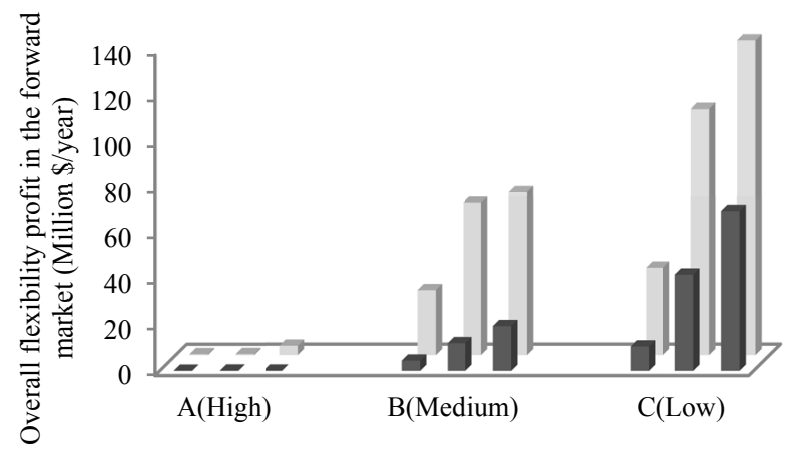

Fig. 12. Overall profit (Million $\$$ /year) from flexibility services in the forward market with and without a $6 \mathrm{~h}$ rolling clearing

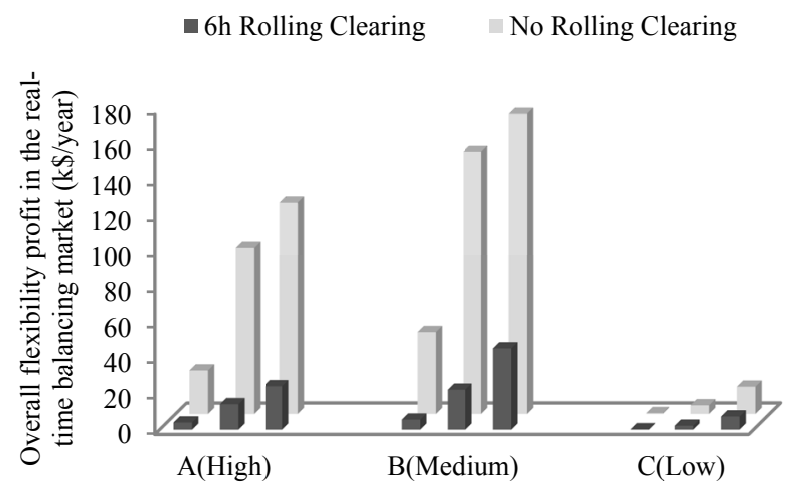

Fig. 13. Overall profit ( $\mathrm{k} \$ /$ year) from flexibility services in the real-time market with and without a $6 \mathrm{~h}$ rolling clearing

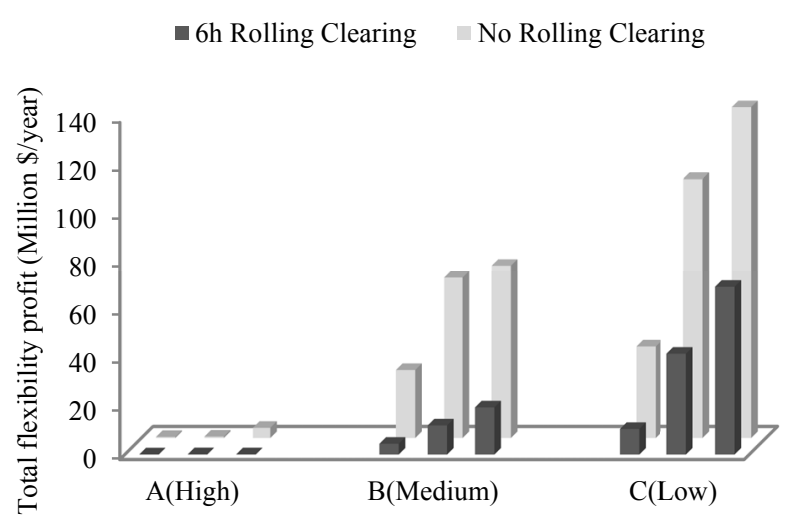

Fig. 14. Total profit (Million \$/year) from flexibility services in the forward and real-time markets with and without a $6 \mathrm{~h}$ rolling clearing

\section{CONCLUSIONS}

This paper proposes a technique to quantitatively evaluate the profit of flexibility services. With increasing wind penetrations in power systems, the need for flexibility services will increase but providing these flexibility services must be profitable if independent generating companies are to build generating units with suitable characteristics. Results show that this profitability depends very much on a tradeoff between 
technical and cost characteristics of the units providing flexibility services. It is also important to consider how much flexibility services is traded in the forward (e.g. day-ahead) market and how much is traded in the real-time balancing market.

The error on the wind forecast and the frequency of a rolling market clearing has a significant influence on this profitability.

The results presented in this paper have considered only the flexibility services provided by conventional generators. However, the proposed technique can be extended to evaluate the profitability of other sources of flexibility, such as storage and demand response. Other sources of uncertainty could also be considered besides the wind forecast error.

\section{REFERENCES}

[1] M. Alhajali, et al., "Impact of wind variability on weakly interconnected power systems," in Power and Energy Society General Meeting, 2010, pp. 1-6.

[2] M. F. Conlon and W. Carr, "Generation adequacy assessment incorporating wind energy capacity," in Universities Power Engineering Conference, 2004. vol. 2, pp. 1014-1018.

[3] Wind Energy - The Facts (WindFacts) [Online]. Available: http://www.wind-energy-the-facts.org

[4] B. Lu and M. Shahidehpour,"Unit commitment with flexible generating units," IEEE Transactions on Power system, vol. 20, pp. 1022-1034, 2005.

[5] L. Shuai, et al., "Unit commitment considering generation flexibility and environmental constraints," in Power and Energy Society General Meeting, 2010, pp. 1-11.

[6] P. Jazayeri, et al., "A Survey of Load Control Programs for Price and System Stability," IEEE Transactions on Power Systems, vol. 20, pp. 1504-1509, 2005.

[7] J. A. F. Moreno, et al., "An integrated tool for assessing the demand profile flexibility," IEEE Transactions on Power Systems, vol. 19, pp. 668-675, 2004.

[8] J. Bai, et al., "A probabilistic reserve market incorporating interruptible load," IEEE Transactions on Power Systems, vol. 21, pp. 1079-1087, 2006.

[9] J. Bai, et al., "A probabilistic reserve market incorporating interruptible load," IEEE Transactions on Power Systems, vol. 21, pp. 1079-1087, 2006.

[10] V. S. V. Silva, et al., "Benefits of Storage and DSM in Transmission Congestion Management in Systems with High Wind Penetration," presented at the 7th International Workshop on Large Scale Integration of Wind Power and on Transmission Networks for Offshore Wind Farms, May, 2008.

[11] E. D. Castronuovo and J. A. P. Lopes, "On the optimization of the daily operation of a wind-hydro power plant," IEEE Transactions on Power Systems, vol. 19, pp. 1599-1606, 2004.

[12] B. C. Ummels, et al., "Integration of large-scale wind power and use of energy storage in the netherlands' electricity supply," IET Renewable Power Generation , vol. 2, pp. 34-46, 2008.

[13] K. Ntotas, et al., "Flexible international exchanges: A possible solution for large \&\#x2014; Scale wind power integration," in PowerTech, 2009 IEEE Bucharest, 2009, pp. 1-8.

[14] J. Ma, D.S.Kirschen, Régine Belhomme, Vera Silva,"Optimizing the flexibility of a portfolio of generating plants," the 17th Power Systems Computation Conference, Stockholm Sweden, 2010.

[15] V.S.V.Silva, "Value of flexibility in systems with large wind penetration," Ph.D Thesis, Imperial College London, London, 2010.

[16] F. Bouffard and M. Ortega-Vazquez, "The value of operational flexibility in power systems with significant wind power generation," in Power and Energy Society General Meeting, 2011, pp. 1-5.

[17] A. Tuohy, et al., "Rolling Unit Commitment for Systems with Significant Installed Wind Capacity," in Power Tech, 2007 IEEE Lausanne, pp. 1380-1385.

[18] B. C. Ummels, "Power System Operation with Larg e-Scale Wind Power in Liberalised Environments," PhD, University Delft, 2009.
[19] D. P. Mendes and D. S. Kirschen, "Assessing pool-based pricing mechanisms in competitive electricity markets," in Power Engineering Society Summer Meeting, 2000. vol. 4, pp. 2195-2200.

[20] B. Mary and S. Goran, "Value of Bulk Energy Storage for Managing Wind Power Fluctuations," IEEE Transactions on Energy Conversion, vol. 22, pp. 197-205, 2007.

[21] T. Boehme, et al., "Matching renewable electricity generation with demand," Edinburgh.Feb. 2006.

Juan Ma received her BS and MS degree in Electrical Engineering from Tsinghua University, China, in 2006 and 2008, respectively. She is currently pursuing her Ph.D. degree in the School of Electrical and Electronic Engineering at The University of Manchester, UK. Her research interests include power system operation with wind penetration and electricity market.

Vera Silva received a B.Sc. and M.Sc. degrees from the University of Porto, Portugal, in 1999 and 2003, respectively, and a Ph.D in Electrical Engineering from the Imperial College London in 2010. She is a Project Manager and Research Engineer at the Department of Economic and Technical Analysis of Energy Systems in the R\&D Division of EDF SA. Before joining EDF she held a position of Assistant Professor at the Polytechnic Institute of Porto (2000-2005) and a research position at Imperial College London (2005-2009). Her research interests include integration of intermittent generation, demand side management and electric vehicles. She was a member of former CIGRE WG C6.09 on "Demand Side Response"

Luis F. Ochoa (S'01-M'07) is a Lecturer in Smart Distribution Networks at The University of Manchester, UK. He received the B.Eng. degree from UNI, Lima, Peru, in 2000 and the M.Sc. and Ph.D. degrees from UNESP, Ilha Solteira, Brazil, in 2003 and 2006, respectively. From 2007 to 2010, he was a Research Fellow at the University of Edinburgh, U.K.

His current research interests include network integration of distributed energy resources and distribution system analysis.

Daniel S. Kirschen (M'86, SM'91, FM'07) received the electrical and mechanical engineer's degree from the Université Libre de Bruxelles, Bruxelles, Belgium, in 1979 and the M.S. and Ph.D. degrees from the University of Wisconsin-Madison in 1980 and 1985, respectively. He is currently Close Professor of Electrical Engineering at the University of Washington.

Régine Belhomme (S'83, M'91) received the Electrical Engineering degree in 1986 and the $\mathrm{PhD}$ degree in 1990, both from the University of Liège, Belgium. She is Project Manager and Senior Engineer in the Department of Economic and Technical Analysis of Energy Systems, in the R\&D Division of EDF SA. Before joining EDF, she was with the Research Institute of HydroQuebec (IREQ), Canada, where she carried out studies on the integration of Distributed Generation (DG) into the Hydro-Quebec distribution network. She joined EDF R\&D in 1998 and her main activities first concerned the integration of DG and Renewable into transmission and distribution power systems. She is now involved in activities on demand side integration and the development of active demand. She is the Technical Manager of the ADDRESS European Project. She is a member of IEEE, CIGRE and SEE. She was a member of former CIGRE WG C6.09 on "Demand Side Response" and she is a member of CIGRE WG C6.20 on the "Integration of electric vehicles into power systems". 